\title{
A prática como componente curricular na formação do professor de Biologia: avanços e desafios na UFRPE
}

The practice as a curricular component in teacher education: advances and challenges in UFRPE

\author{
Alessandra Maria Pereira Martins da SILVA ${ }^{1}$ \\ Zélia Maria Soares JÓFILI² \\ Ana Maria dos Anjos CARNEIRO-LẼ̃O ${ }^{3}$
}

\section{RESUMO}

O objetivo deste estudo é investigar o potencial da Prática como Componente Curricular (PCC) para a efetiva formação do professor de Biologia. O campo de pesquisa foi o curso de Licenciatura Plena em Ciências Biológicas da Universidade Federal Rural de Pernambuco - UFRPE. Foram analisados os documentos oficiais que tratam das disciplinas de PCC, entrevistados três docentes responsáveis pela regência dessas disciplinas no curso sob estudo e dez estudantes que já haviam cursado todas as disciplinas de PCC. Os resultados evidenciam que o curso investigado atende ao recomendado nas normas vigentes que regem a atividade de PCC. No entanto, com relação aos conhecimentos enfatizados e às competências mobilizadas, percebemos incoerências entre o descrito nos documentos, o discurso dos docentes e a percepção dos estudantes. Apesar dessas incoerências há o predomínio na ênfase ao conhecimento teórico do conteúdo específico e do pedagógico e a mobilização das competências pedagógicas e da reflexiva. Ficou claramente estabelecida a necessidade de ampliar a discussão a respeito do sentido da atividade de PCC na formação dos professores, além de ajustes e adequações na vivência das disciplinas de PCC, para que possam, de fato, favorecer a formação docente e atender ao perfil oficial almejado.

Palavras-chave: Prática como Componente Curricular, Perfil profissional, Conhecimento, Competências, Formação de Professores de Biologia.

\section{ABSTRACT}

The purpose of this study is inquiry the potential of the Practice as Curriculum Component (PCC) to the effective formation to the Biology teacher. The Searching Camp was the Graduation Course in Biological Sciences at Universidade Federal Rural de Pernambuco - UFRPE, where was performed an analysis of official documents dealing with subjects of PCC, interviewing three responsible teachers for conducting the Course in these disciplines study and ten students who had attended all disciplines of PCC. However about the Knowledge emphasized and Skills mobilized, the results showed inconsistencies between the documents described in the speech of teachers and students' perceptions. Despite these inconsistencies there is the predominant emphasis on the theoretical knowledge of the specific and the pedagogical content, and the mobilizing of pedagogical Skills and their reflection. It has been clearly established the necessity to broaden the discussion about the meaning of PCC activity in teacher training. In addition to adjustments and adaptations in living subjects of PCC so that they can in fact promote teacher grade training and meet the official profile desired.

Keywords: Practice as Curriculum Component, Professional Profile, Knowledge, Skills, Biology Teachers Education.

\footnotetext{
${ }^{1}$ Secretaria de Educação de Pernambuco - SEDUC/PE, alessandra_biologa@hotmail.com

2 Programa de Pós-Graduação em Ensino de Ciências da Universidade Federal Rural de Pernambuco - PPGEC/UFRPE, jofili@gmail.com

${ }_{3}^{3}$ PPGEC/UFRPE, Programa de Pós-Graduação em Ensino de Ciências da Universidade Federal Rural de Pernambuco PPGEC/UFRPE, amanjos50@gmail.com
} 


\section{Introdução}

Atualmente, um dos grandes desafios do Brasil é melhorar a qualidade da educação e não concebemos essa melhoria sem direcionarmos o olhar para os cursos de formação de professores para a Educação Básica. É nessa formação que os futuros professores constroem os fundamentos necessários a sua prática docente: conhecimentos, competências e habilidades.

Tais fundamentos deverão ser construídos ao longo do curso de formação, e para isso, necessitam de momentos onde os estudantes possam colocá-los em uso. Assim, no intuito de proporcioná-los, emergiu a necessidade de um currículo que superasse a ideia do modelo $3+1$ de formação, considerado pelas Diretrizes Curriculares Nacionais - DCN como insuficiente para o processo formativo do professor. Em tal modelo os estudantes contemplavam, ao longo de três (3) anos, os conteúdos específicos relacionados ao curso, postergando ao último ano os momentos de prática no ambiente escolar.

Os cursos de formação de professores têm papel fundamental no processo da construção do profissional docente e, junto com essa responsabilidade, a preocupação em proporcionar aos futuros professores, um curso que lhes ofereça as condições necessárias para o exercício da sua função.

Para que tenhamos professores que cumpram seu papel no processo educativo e promovam na educação brasileira as mudanças necessárias para formar cidadãos críticos e éticos, estes precisam passar por cursos que propiciem uma formação condizente com a responsabilidade por eles assumida perante a sociedade.

Diante dessa responsabilidade, os cursos precisaram passar por uma reforma curricular que contemple alguns pontos necessários à formação de professores, para que isso se reflita na educação básica (MIRANDA, 2006). Em termos de currículo, este deverá contemplar o repertório de conhecimentos necessários aos professores em formação; promover um tratamento adequado dos conteúdos; ampliar a atuação profissional do professor - não o limitando apenas a ministrar aulas -, mas fazendo-o se sentir parte integrante do processo de formação dos alunos e ampliação da concepção de prática.

No Brasil, este processo teve início com a Lei de Diretrizes e Bases da Educação Nacional - LDBEN (BRASIL, 1996) e foi disciplinado através das Resoluções CNE/CP nº 1 e 2 de 2002 (BRASIL, 2002c e 2002d) que trouxeram no seu bojo ideias inovadoras e reformulações. Uma delas foi a inserção da atividade denominada Prática como Componente Curricular (PCC) nos cursos de formação de professores. As Instituições de Ensino Superior- IES de todo o país vêm implementando reformas em suas estruturas curriculares. Por ser relativamente nova, se comparadas às grandes discussões na educação, ainda é muito confuso o entendimento do que seja a PCC, qual seu objetivo ou finalidade, qual a melhor forma de organizar as disciplinas que a compõem, na matriz curricular e como deve ser desenvolvida nos cursos de formação. Embora permeadas por estes questionamentos, essas disciplinas assim como qualquer outra contida na matriz curricular de um curso, têm por objetivo a construção dos conhecimentos e a mobilização das competências, a fim de atender ao perfil profissional do curso no qual estão inseridas.

De acordo com o Parecer CNE/CES 15/2005 (BRASIL, 2005, p. 3) a atividade de PCC é definida como "[...] conjunto de atividades formativas que proporcionam experiências de aplicação de conhecimentos ou de desenvolvimento de procedimentos próprios ao exercício da docência [...]." 
Ou seja, as PCC não têm o propósito de promover a construção do conhecimento específico e/ou pedagógico. Elas são caracterizadas como "espaços" ao longo do processo formativo no qual os estudantes deverão mobilizar as competências e conhecimentos construídos durante a sua formação inicial (conteúdos específicos e pedagógicos) e realizar, sob a mediação do professor, a transposição didática da "ciência do cientista" para a sala de aula da educação básica.

Por configurar-se como um local onde conhecimentos são enfatizados e competências são mobilizadas, alguns pontos a respeito da PCC precisam ser melhor discutidos. A definição trazida pelo Parecer CNE/CES 15/2005 (BRASIL, 2005) menciona a "aplicação de conhecimentos", mas em relação às atividades trabalhadas nas disciplinas de PCC, quais conhecimentos são enfatizados? Quais competências são mobilizadas? Qual o propósito de enfatizar determinado conhecimento e mobilizar certas competências e não outras? Que profissional docente deseja formar? Uma vez resolvidas essas questões, os cursos de formação deverão elaborar sua matriz curricular, elencando disciplinas que descrevam em seus planos de ensino as ações norteadoras com vistas a garantir a formação do profissional almejado.

Existe uma relação estreita entre o perfil profissional do curso e as disciplinas que compõem sua matriz curricular. Tendo em vista a necessidade normativa de inserção da PCC nos cursos é válido investigar se essa inserção, do modo como está sendo feita, atende (ou não) à formação do profissional almejado.

Diante disso, este estudo se propõe a investigar o potencial da Prática como Componente Curricular para a efetiva formação do professor de Biologia, identificando a sua configuração no curso de Licenciatura Plena em Ciências Biológicas, os conhecimentos e as competências descritos nos documentos oficiais (planos de ensino) que tratam das disciplinas de PCC e os vivenciados nas respectivas disciplinas, na perspectiva de alunos e professores e analisando a relação entre os conhecimentos enfatizados e as competências mobilizadas, identificadas no estudo, com a formação do professor de Ciências e Biologia.

\section{Conhecimentos e competências inerentes ao professor: o caso da Biologia}

Uma das grandes preocupações dos cursos de formação de professores é proporcionar aos seus licenciandos o conhecimento da matéria a ser ensinada (o saber), bem como as estratégias para viabilizar a aprendizagem de seus alunos (o saber-fazer). No entanto, vários estudos tendo como sujeitos de pesquisa graduandos, mestrandos e docentes da educação básica e do ensino superior, têm demonstrado a fragilidade da sua construção conceitual e metodológica (FABRÍCIO et al., 2006; LOPES, 2007; SÁ, 2007; PEREIRA, 2008; ARCANJO, 2009; MEDEIROS, 2011).

Para que possamos superar esta fragilidade e assim poder promover uma formação profissional que privilegie os pilares necessários ao exercício da atividade docente, faz-se necessário que os cursos de formação possam oferecer ao futuro professor, os conhecimentos mínimos necessários ao exercício da sua atividade. Mas afinal, quais são esses conhecimentos?

Segundo Mizukami (2004, p. 38):

A base de conhecimento para o ensino consiste de um corpo de compreensões, conhecimentos, habilidades e disposições que são 
necessários para que o professor possa propiciar processos de ensinar e de aprender, em diferentes áreas de conhecimento, níveis, contextos e modalidades de ensino.É mais limitada em cursos de formação inicial, e se torna mais aprofundada, diversificada e flexível a partir da experiência profissional refletida e objetivada. [...] Para Shulman (1986,1987), a base de conhecimento se refere a um repertório profissional que contém categorias de conhecimento que subjazem à compreensão que o professor necessita para promover aprendizagens dos alunos. Trata-se de um modelo que foi desenvolvido considerando o conceito de ensino como profissão, envolvendo delimitação de campo de conhecimento que pode ser sistematizado e partilhado com outros: os profissionais do ensino necessitam de um corpo de conhecimento profissional codificado e codificável que os guie em suas decisões quanto ao conteúdo e à forma de tratá-lo em seus cursos e que abranja conhecimento pedagógico quanto conhecimento da matéria.

Shulman (1987) especifica sete categorias de base de conhecimento para a docência que transformam uma pessoa em um professor competente. São elas:

conhecimento do conteúdo;

conhecimento pedagógico (conhecimento didático geral), tendo em conta, especialmente, aqueles princípios e estratégias gerais de condução e organização da aula, que transcendem o âmbito da disciplina;

conhecimento do currículo, considerado como um especial domínio dos materiais e os programas que servem como "ferramentas para o ofício" do docente;

conhecimento dos alunos e da aprendizagem;

conhecimento dos contextos educativos, que abarca desde o funcionamento do grupo ou da aula, a gestão e financiamento dos distritos escolares, até o caráter das comunidades e culturas;

conhecimento didático do conteúdo, destinado a esse especial amalgama entre matéria e pedagogia, que constitui uma esfera exclusiva dos professores, sua própria forma particular de compreensão profissional;

conhecimento dos objetivos, as finalidades e os valores educativos, e de seus fundamentos filosóficos e históricos.

Para fins didáticos, esses conhecimentos podem ser agrupados em apenas três, são eles: conhecimento do conteúdo específico, conhecimento pedagógico geral e conhecimento pedagógico do conteúdo. Segundo Shulman (1986), o conhecimento do conteúdo se refere ao conhecimento disciplinar específico, no nosso caso, o da biologia. Desse modo, para que o professor possa ensinar, é imprescindível que conheça a matéria a ser ensinada. No entanto, apesar de essencial, o domínio do conhecimento específico não é suficiente para tornar o professor apto a lecionar. De acordo com Wilson, Shulman e Richert (1987, p. 109 apud MIZUKAMI, 2004, p. 39).

Embora uma compreensão pessoal da matéria seja necessária, não é condição suficiente para que se seja capaz de ensinar. Os professores devem encontrar formas de comunicar conhecimentos para os outros. (...) Eles devem ter dois tipos de conhecimento da matéria: conhecimento da área tanto em seus aspectos genéricos quanto em suas especificidades e conhecimento de como ajudar seus estudantes a entender a matéria. 
Assim, para poder ajudar os estudantes na compreensão da matéria, o professor precisará também do conhecimento pedagógico geral. Tal conhecimento vai além do conhecimento do conteúdo específico, pois se configura como aquele que está relacionado ao contexto escolar, ao conhecimento dos estudantes e ao conhecimento do processo de ensino e aprendizagem. Engloba os princípios ou estratégias de gestão e organização de classe, úteis para ensinar o conteúdo específico e, sendo assim, é fundamental que o professor, para o exercício da atividade docente, conheça e leve em consideração o âmbito escolar e tudo o que vem agregado a ele.

Para que os conhecimentos trazidos por Shulman (1986) possam, de fato, ser mobilizados e encurtar a distância entre a teoria e a prática é necessário que o professor possua competências que possam ser mobilizadas quando oportuno e, assim, favorecer o processo de ensino-aprendizagem.

As competências necessárias ao professor de biologia, as quais nos referimos, representam, de acordo com Perrenoud (2000), a faculdade de mobilizar um conjunto de recursos cognitivos para solucionar, com pertinência e eficácia, uma série de situações. Para Zabalza (2006, p.70), competência é o "conjunto de conhecimentos e habilidades que os sujeitos necessitam para desenvolver algum tipo de atividade". Este objetivo conferido às competências, de promover alguma atividade, também é defendido por Álvarez e Gallego (2006, p.23) que consideram as competências como:

[...] o conjunto de conhecimentos, habilidades e atitudes necessários para desempenhar uma ocupação dada e a capacidade de mobilizar e aplicar estes recursos em um entorno determinado, para produzir um resultado definido (ÁLVAREZ E GALLEGO, 2006 p. 23)

Zabalza (2006) sugere que os futuros docentes necessitariam ter as seguintes competências:

1) planejar o processo de ensino-aprendizagem;

2) selecionar e preparar os conteúdos disciplinares;

3) oferecer informações e explicações compreensíveis e bem organizadas (competência comunicativa);

4) manejar as novas tecnologias;

5) conceber a metodologia e organizar as atividades,

6) comunicar-se e relacionar-se com os alunos;

7) tutoria;

8) avaliar;

9) refletir e pesquisar sobre o ensino;

10) identificar-se com a instituição e trabalhar em equipe.

De acordo com o autor, as competências relacionadas ao contexto escolar têm pouco enfoque, limitando-se a apenas uma. A ênfase maior são para as competências relacionadas ao exercício da prática docente. Em relação a estas, consideramos serem as competências que deveriam ser mais potencializadas e efetivamente consolidadas ao longo do curso de formação inicial dos professores. Em função da sua importância na formação docente e por acreditarmos que são as que mais se aproximam do nosso objeto de estudo, iremos nos ater a estas competências.

No caso do professor de Ciências e de Biologia, Carvalho e Gil-Pérez (2011) discutem novos pontos da formação deste profissional relacionados ao ato de ensinar. Em seus questionamentos iniciais, refletiram sobre: $\bigcirc$ que deverão saber e saber-fazer os 
professores de Ciências? A partir dessas indagações elencaram aspectos triviais ao professor e ao ensino que enfatizam a ideia de aprendizagem como construção de conhecimento com as características de uma pesquisa científica e com a necessidade de transformar o pensamento espontâneo do professor (CARVALHO e GIL-PÉREZ, 2011). Estes pontos foram denominados pelos autores como necessidades formativas do professor de ciências. A saber:

A ruptura com visões simplistas sobre o ensino de Ciências;

Conhecer a matéria a ser ensinada;

Questionar as ideias docentes de "senso comum" sobre o ensino e a aprendizagem das Ciências;

Adquirir conhecimentos teóricos sobre a aprendizagem das Ciências;

Saber analisar criticamente o "ensino tradicional";

Saber preparar atividades capazes de gerar uma aprendizagem efetiva;

Saber dirigir o trabalho dos alunos;

Saber avaliar;

Adquirir a formação necessária para associar ensino e pesquisa didática.

Diante do exposto, reconhecendo a importância dos conhecimentos e das competências no processo da formação docente, é pertinente saber de que maneira a PCC se insere nesse contexto.

\section{A prática como componente curricular nos documentos oficiais}

Entendemos que se faz necessário estabelecer algumas diferenças entre a prática de ensino e a prática como componente curricular, uma vez que o não esclarecimento delas vem provocando algumas confusões quanto à elaboração do currículo das instituições de ensino e à profissionalização dos professores.

A prática de ensino há algumas décadas estava relacionada às atividades inerentes ao exercício da profissão de professor. O Conselho Estadual de Educação do Estado de São Paulo (23.09.1997) destacou, no relatório do conselho pleno, que a prática de ensino abrange a aprendizagem de noções teóricas, experiências de regência de classe e realização de estágio. Desta forma, a concepção de prática de ensino, como disciplina, estava quase que restrita a ideia de estágio, sendo realizada no último ano do curso de formação e desarticulada das demais disciplinas do curso.

No entanto, com a ampliação das discussões no âmbito educacional, percebeu-se que dada a sua importância na formação inicial dos professores, a prática de ensino necessitaria de uma maior inserção nas disciplinas teóricas, buscando estabelecer com elas uma articulação que possibilitasse a correlação entre teoria e prática, originando assim, a Prática como Componente Curricular - PCC. Assim sendo, no ano de 2002, o Parecer CNE/CP no 9/ 2001 (BRASIL, 2002a, p. 9), destaca que:

[...] uma concepção de prática mais como componente curricular implica vê-la como uma dimensão do conhecimento, que tanto está presente nos cursos de formação nos momentos em que se trabalha na reflexão sobre a atividade profissional, como durante o estágio nos momentos em que se exercita a atividade profissional.

Desta forma, a PCC passa a ter uma dimensão mais abrangente visando a promover essa articulação intrínseca com as demais disciplinas, entendendo dessa forma, que o 
currículo com uma carga horária de 300 horas seria insuficiente para promover uma elevação do padrão de qualidade nos cursos de licenciatura e assim, consequentemente, proporcionar uma formação que atendesse às necessidades da profissionalização do professor.

Assim, a resolução CNE/CP 2 de 19 de fevereiro de 2002 (BRASIL, 2002d), em seu artigo $1^{\circ}$ afirma que:

A carga horária dos cursos de Formação de Professores da Educação Básica, em nível superior, em curso de licenciatura, de graduação plena, será efetivada mediante a integralização de, no mínimo, 2800 (duas mil e oitocentas) horas. [...]. (BRASIL, 2002d, p.9).

Desta carga horária mínima, 400 (quatrocentas) horas seriam destinadas à prática como componente curricular e vivenciadas ao longo do curso de formação de professores. Outras 400 (quatrocentas) horas seriam destinadas ao estágio curricular supervisionado a partir do início da segunda metade do curso.

Apesar dessa recomendação, muitas são as discussões a respeito da forma como a ampliação da carga horária da PCC será estruturada e desenvolvida dentro dos cursos de licenciatura em Ciências Biológicas. Na tentativa de esclarecer a forma como esta será distribuída, o Conselho Nacional de Educação - CNE recomenda que a inserção ocorra desde o início do processo formativo, se estenda por todo ele e seja formalmente explicitada no Projeto Político Pedagógico - PPP do curso.

[...] Assim, ela deve ser planejada quando da elaboração do projeto pedagógico e seu acontecer deve se dar desde o início da duração do processo formativo e se estender ao longo de todo o seu processo. Em articulação intrínseca com o estágio supervisionado e com as atividades de trabalho acadêmico, ela concorre conjuntamente para a formação da identidade do professor como educador. (BRASIL, 2002d, p.9).

Porém, apesar desta recomendação, coube a cada IES, através de seus Colegiados, discutir e estabelecer a forma de sua inserção. O Parecer do CNE/CES n. 15/2005 (BRASIL, 2005, p. 3) sugeriu formas de estruturar nos currículos dos cursos de licenciatura as atividades caracterizadas como PCC.

[...] As atividades caracterizadas como prática como componente curricular podem ser desenvolvidas como núcleo ou como parte de disciplinas ou de outras atividades formativas. Isto inclui as disciplinas de caráter prático relacionadas à formação pedagógica, mas não aquelas relacionadas aos fundamentos técnico-científicos correspondentes a uma determinada área do conhecimento. (BRASIL, 2005, p. 3).

Estas disciplinas de caráter prático referidas no supracitado parecer, são aquelas onde as atividades inerentes ao exercício da docência são vivenciadas. Porém, algumas indagações são feitas com relação à forma como esta atividade deverá ser desenvolvida durante a formação docente. Assim, de acordo o Parecer CNE/CES 15/2005 (BRASIL, 2005, p. 3) a atividade de PCC é definida como:

[...] conjunto de atividades formativas que proporcionam experiências de aplicação de conhecimentos ou de desenvolvimento de procedimentos próprios ao exercício da docência. Por meio destas atividades, são colocados em uso, no âmbito do ensino, os conhecimentos, as 
competências e as habilidades adquiridos nas diversas atividades formativas que compõem o currículo do curso [...].

Assim, por assumir esta responsabilidade, as PCC teriam um papel relevante dentro do processo formativo, o de promover a articulação do saber específico (teoria) com a aplicação dele (prática) no campo do ensino, mas para que isto ocorra, faz-se necessário que os licenciandos já tenham o saber específico construído e as competências específicas igualmente desenvolvidas, pois de acordo com o supracitado parecer, a atividade de PCC é o momento de colocar estes pilares da formação em uso.

\section{Metodologia}

Participaram desta investigação três (3) docentes que atuam no curso de Licenciatura Plena em Ciências Biológicas da UFRPE, aqui nomeados de P1, P2 e P3, escolhidos de acordo com os seguintes critérios: lecionar ou ter lecionado pelo menos uma das disciplinas de PCC nos últimos dois (2) anos e disponibilidade em participar da pesquisa. Além dos docentes, colaboraram com este estudo dez (10) discentes, distribuídos entre os turnos diurno e noturno, escolhidos aleatoriamente, com a condição de terem cursado todas as disciplinas de PCC.

Para identificarmos os conhecimentos enfatizados e as competências mobilizadas pelas disciplinas de PCC, optamos por realizar uma análise dos documentos oficiais do curso, a aplicação de um questionário com os discentes e a realização de uma entrevista semiestruturada com os docentes do curso. A entrevista, gravada em áudio, teve a função, também, de coletar dados acerca de como planejam/estruturam suas aulas focadas nesse componente curricular.

\section{Resultados e discussão}

Atualmente, o curso de Licenciatura Plena em Ciências Biológicas da UFRPE conta com duas (2) matrizes curriculares. A mais recente contempla a PCC, que é vivenciada em sete (7) disciplinas, organizadas num núcleo comum, e não pulverizadas nas demais disciplinas do conteúdo específico. São ofertadas a partir do $2^{\circ}$ período do curso e se estendem até o final dele, atendendo assim ao que sugere o parecer do CNE/CP 028/2001 (BRASIL, 2002b).

Dutra (2010), ao se referir à organização da PCC, valoriza a questão de que este componente curricular "deve ser desenvolvido ao longo do curso de graduação e vivenciado em diferentes contextos onde se desenvolvam atividades vinculadas à futura profissão do licenciando".

Em relação à carga horária destinada às disciplinas de PCC, observamos que o curso atende ao que determina a Resolução CNE/CP 2 (BRASIL, 2002d) pois destina às PCC 405 horas/aula, cinco (5) a mais do que o solicitado no documento oficial.

Analisando o perfil profissional, considerando que este norteará a construção da matriz curricular e a escolha dos conteúdos que serão trabalhados durante o processo de formação, constatamos que os conhecimentos a serem enfatizados descritos no perfil profissional, apontam para um profissional que domine o conhecimento teórico e prático dos conteúdos específicos e pedagógicos. Dessa forma, atenderiam ao recomendado no Parecer CNE/CES 15/2005 (BRASIL, 2005, p.3). 
Focando no conhecimento enfatizado descrito pelo perfil profissional do curso e na legislação vigente, que regulamenta a atividade de PCC, poderíamos afirmar que no que tange à disposição na matriz curricular e distribuição da sua carga horária, o curso investigado está atendendo ao recomendado pelos pareceres e resoluções. Além disso, por serem ministradas concomitantemente ou no semestre seguinte às disciplinas do conhecimento específico, as disciplinas de PCC estariam favorecendo a formação do professor de biologia. Porém, como as disciplinas de Prática de Morfologia e Fisiologia e Prática de Genética, estão dispostas na matriz curricular antes de algumas disciplinas do conhecimento pedagógico, os estudantes em formação, não teriam os conhecimentos pedagógicos necessários para fazer as devidas transposições didáticas.

A respeito dos conhecimentos enfatizados descritos nos planos de ensino das disciplinas de PCC, percebemos que estes priorizam o conhecimento teórico, seja do conteúdo específico ou do conteúdo pedagógico, em detrimento do conhecimento prático, não atendendo, desse modo, ao recomendado à atividade de PCC. Por dar pouca ênfase à atividade prática, sinaliza para a formação de um profissional que terá seu perfil direcionado à formação acadêmica. Porém, quando nos voltamos para os conhecimentos enfatizados, constatamos que na opinião dos discentes, a maioria das disciplinas atende ao descrito no PPP do curso por enfatizar quase todos os conhecimentos investigados, com exceção das disciplinas de Prática de Saúde e Epidemiologia (PSE) e Prática de Genética (PG), que precisariam de algumas alterações e inserções.

Os conhecimentos identificados na prática dos docentes (P1 e P2) se contrapõem aos identificados nos planos de ensino das disciplinas de PCC, pois esses docentes dão ênfase maior ao conhecimento pedagógico prático, demonstrando interesse em proporcionar aos estudantes em formação, aplicação do conhecimento, conforme solicitado no Parecer CNE/CES 15/2005 (BRASIL, 2005, p. 3). Por sua vez, P3 atende ao que está descrito nos planos de ensino (ênfase na teoria).

Wilson, Shulman e Richert (1987, p. 109 apud MIZUKAMI, 2004, p. 39) ao descreverem o conhecimento pedagógico geral (SHULMAN, 1986,1987) afirmam que os professores

[...] devem ter conhecimento das formas de transformar o conteúdo considerando os propósitos do ensino (...) que inclua compreensão pessoal do conteúdo específico, assim como conhecimento das formas de comunicar tal compreensão, propiciar desenvolvimento do conhecimento da matéria na mente dos alunos.

Desse modo, os planos de ensino, por enfatizarem o conhecimento teórico tanto do conteúdo específico quanto do pedagógico e, os docentes em sua maioria, enfatizarem os conhecimentos teórico e prático do conteúdo pedagógico, não estariam de acordo com o perfil profissional, que recomenda a ênfase nos conhecimentos teórico e prático do conteúdo específico e pedagógico. Dessa forma, não favorecem plenamente a formação docente almejada. Já na percepção dos alunos, a maioria das disciplinas de PCC atende ao descrito no PPP do curso e, consequentemente, favorece a formação do professor ao enfatizar todos os conhecimentos investigados. Esta divergência é melhor visualizada no quadro 1. 
Quadro 1 - Visão geral dos conhecimentos enfatizados pelos planos de ensino das disciplinas de PCC e na percepção dos sujeitos da pesquisa

\begin{tabular}{|c|c|c|c|}
\hline \multirow{2}{*}{$\begin{array}{c}\text { Tipos de } \\
\text { conhecimento }\end{array}$} & \multicolumn{3}{|c|}{ Sujeitos da pesquisa } \\
\cline { 2 - 4 } & Planos de ensino & Discentes & Docentes \\
\hline TCE & $X$ & $X$ & \\
\hline PCE & & $X$ & \\
\hline TCP & $X$ & $X$ & $X$ \\
\hline PCP & & $X$ & $X$ \\
\hline
\end{tabular}

Fonte: Dados organizados pelas Autoras. Legenda: TCE - Teórico Conteúdo Específico; PCE - Prático do Conteúdo Específico; TCP - Teórico do Conteúdo Pedagógico; PCP - Prático do Conteúdo Pedagógico.

Os resultados obtidos apontam algumas contradições: dois professores discordam do prescrito nos planos de ensino e informam trabalhar a TCP e a PCP. Apesar disto, os estudantes percebem diferentemente. Para eles os professores trabalham tanto a teoria como a prática dos conhecimentos específicos e pedagógicos (ou seja, além da TCP e PCP, trabalham também a TCE e PCE). No entanto, apesar disto, no final os estudantes se sentem despreparados! Onde está o problema?

No que tange às competências, o perfil profissional descrito no Projeto Político Pedagógico - PPP do curso sinaliza para um professor que mobilize as competências pedagógicas, reflexivas e tecnológicas, haja vista que ao mobilizar estas três competências, atenderia a almejada "preparação adequada à aplicação pedagógica do conhecimento e experiências de Biologia e áreas afins na atuação profissional como educador".

Os planos de ensino das disciplinas de PCC sinalizam para a formação de um profissional capaz de propor experiências de aplicação dos conhecimentos, promover atividades problematizadoras, desenvolver intervenções didáticas diferenciadas e refletir sobre as experiências. Desse modo, apesar de mobilizarem um pouco dos elementos descritores da competência pedagógica, estão ainda muito aquém do almejado pelo perfil, pois necessitariam inserir em seus documentos a competência tecnológica, não encontrada nos documentos.

Em relação às competências mobilizadas durante a vivência das disciplinas de PCC, os discentes apontam para a formação de um profissional capaz de promover atividades problematizadoras e contextualizadas e com uma visão voltada para a reflexão sobre as atividades propostas de aplicação do conhecimento. Quanto aos docentes, estes sinalizam em sua maioria, para a mobilização de competências que levem à formação de docente capaz de propor experiências de aplicação destes conhecimentos e, da mesma forma que os percebidos pelos estudantes, um profissional docente que reflita sobre as ações inerentes ao exercício da docência.

A contextualização, uma das competências investigadas, é uma grande aliada na promoção da construção dos conhecimentos científicos, como um meio de aproximar a ciência contida nos livros da ciência do dia-a-dia dos estudantes. Santos (2007, p.5) afirma que a contextualização tem os seguintes objetivos:

[...] (1) desenvolver atitudes e valores em uma perspectiva humanística diante das questões sociais relativas à ciência e à tecnologia; (2) auxiliar na aprendizagem de conceitos científicos e de aspectos relativos à natureza da ciência; e (3) encorajar os alunos a relacionar suas experiências escolares em ciências com problemas 
Observa-se que a competência tecnológica, assim como constatado nos documentos oficiais, também não é priorizada pelos professores (com exceção de P3), ao ministrarem suas aulas, como também não é apontada pelos discentes. Por estarmos hoje inseridos num mundo permeado por tecnologia, faz-se necessário que os professores estejam preparados para usar esse recurso em prol do processo educacional, pois, segundo Gadotti (2000, p.7), "as novas tecnologias criaram novos espaços do conhecimento". Entretanto, é preciso saber utilizar este recurso em prol da educação, pois apenas incorporar sem saber usufruir não oportunizará satisfatoriamente o processo educacional. Neste aspecto, Liguori (1997) frisa:

\section{[...] as instituições educacionais enfrentam o desafio não apenas de incorporar as novas tecnologias como conteúdos do ensino, mas também reconhecer e partir das concepções que as crianças têm sobre estas tecnologias para elaborar, desenvolver e avaliar práticas pedagógicas que promovam o desenvolvimento de uma disposição reflexiva sobre os conhecimentos e os usos tecnológicos. (LIGUORI, 1997, p.85).}

Sobre a competência pedagógica é possível perceber que esta é mobilizada apenas no que diz respeito à promoção de experiências de aplicação do conhecimento e ao desenvolvimento de intervenções didáticas diferenciadas, mas isto apenas é encontrado nos planos de ensino e nos docentes. Curioso é que estes descritores da competência pedagógica, não são percebidos pelos alunos em formação, conforme pode ser visto no quadro 2.

Esta divergência nos leva a pensar que os docentes, apesar de atenderem aos planos de ensino das disciplinas, não estariam usando os recursos metodológicos disponíveis em suas aulas, como afirmam, ou os alunos não estão conseguindo identificar as ações dos professores como possibilidades metodológicas (recursos, ferramentas) viabilizadoras do processo ensino-aprendizagem.

É possível notar, através do quadro 2, que outro descritor da competência pedagógica "resgatar os conhecimentos prévios" não é mobilizado pelos planos de ensino, nem percebido pelos discentes, apesar de P3 afirmar que o mobiliza.

Quadro 2 - Visão geral das competências mobilizadas pelos planos de ensino e sujeitos da pesquisa

\begin{tabular}{|c|c|c|c|c|}
\hline \multirow[t]{2}{*}{ Competências } & \multirow[t]{2}{*}{ Descrição } & \multicolumn{3}{|c|}{ Sujeitos da pesquisa } \\
\hline & & $\begin{array}{l}\text { Planos de } \\
\text { ensino }\end{array}$ & Discentes & Docentes \\
\hline \multirow[t]{5}{*}{ Pedagógica } & Resgatar os conhecimentos prévios & & & ** \\
\hline & Propor experiências de aplicação do conhecimento & $x$ & & $x$ \\
\hline & Problematizar & $x$ & $x$ & \\
\hline & Contextualizar & & $X$ & \\
\hline & Desenvolver intervenções didáticas diferenciadas & $x$ & & $x$ \\
\hline Tecnológica & Utilizar recursos tecnológicos & & & * \\
\hline Reflexiva & $\begin{array}{l}\text { Refletir sobre as experiências de aplicação do } \\
\text { conhecimento }\end{array}$ & $x$ & $x$ & $x$ \\
\hline
\end{tabular}

Fonte: Dados organizados pela Autora. Legenda: ** Identificado em P1 e P3, * Apenas identificado em P3

Assim, podemos perceber que os planos de ensino seriam os que mais se aproximam do requerido pelo perfil profissional do curso, embora negligenciem aspectos importantes ao exercício da docência. Tendo em vista que os docentes não mencionam mobilizar muitas 
competências e os discentes não apontam tal mobilização, fica claro que não estariam favorecendo a formação almejada.

\section{Considerações finais}

O conflito de alguns resultados nos levou a considerar que a recente inserção da PCC no curso investigado, ainda não conseguiu se configurar com uma área definida e distinta das demais dentro do processo de formação inicial dos professores, como é o caso do conteúdo específico, da didática, e do estágio supervisionado. Isto poderia estar dificultando a descrição por aqueles que elaboram os planos de ensino do que deve ser ensinado: a compreensão do que e como ensinar pelos docentes e, nos discentes, o entendimento da importância destas disciplinas no seu processo formativo. Acreditamos que estes conflitos permanecerão enquanto não se discutir o sentido das PCC na formação do professor.

Para que as disciplinas de PCC entrem em consonância com o perfil profissional almejado pelo curso de Licenciatura em Ciências Biológicas da UFRPE, seja na descrição documental (plano de ensino), seja na vivência prática das disciplinas, essas necessitariam passar por algumas adequações, principalmente no que tange aos conhecimentos. Neste caso, a ênfase deveria ser dada a todos os conhecimentos e todas as competências deveriam ser mobilizadas.

Levando-se em conta que a discussão a respeito dessa atividade é recente, o curso tem seus méritos, pois a forma como a IES estudada implementou nas suas matrizes curriculares a atividade de PCC, garante que essa seja vivenciada pelos discentes ao longo do curso, fato que seria difícil de ocorrer fosse inserida nas disciplinas do conteúdo específico. Entretanto, isso não garante que a PCC contribua para a formação docente, pois para que isto ocorra faz-se necessário primeiramente o entendimento por parte do corpo docente do que seja a atividade e da sua relevância para a formação inicial dos professores.

\section{Referências}

ÁLVAREZ, C. Y e GALLEGO, L. V. Planificar desde competencias para promover el aprendizaje. El reto de la sociedad del conocimiento para el profesorado universitario. Bilbao, España: Universidad de Deusto, 2006.

ARCANJO, J. G. Síntese Protéica: um estudo sobre a formação de conceitos. 2009. 130f. Dissertação (Mestrado em Ensino de Ciências). Universidade Federal Rural de Pernambuco, Recife. 2009.

BRASIL. Ministério da Educação. Conselho Nacional de Educação. Parecer CNE/CP 009/2001 de 18 de janeiro de 2002. Diretrizes Curriculares Nacionais para a Formação de Professores da Educação Básica, em nível superior, curso de licenciatura, de graduação plena. 2002a.

BRASIL. Ministério da Educação. Conselho Nacional de Educação. Parecer CNE/CES 28/2001 de 18 de janeiro de 2002. Dá nova redação ao Parecer CNE/CP 21/2001, que estabelece a duração e a carga horária dos cursos de Formação de Professores da Educação Básica, em nível superior, curso de licenciatura, de graduação plena. 2002b.

BRASIL. Ministério da Educação. Conselho Nacional de Educação. Resolução CNE/CP 1 de 18 de fevereiro de 2002. Institui diretrizes curriculares nacionais para a formação de professores da educação básica, em nível superior, curso de licenciatura, de graduação plena. Diário oficial da união, 09 de abril de 2002. Brasília, DF, 2002c. 
BRASIL. Ministério da Educação. Conselho Nacional de Educação. Resolução CNE/CP 2 de 19 de fevereiro de 2002. Institui a duração e a carga horária dos cursos de licenciatura, de graduação plena, de formação de professores da Educação Básica em nível superior. Diário oficial da união, 04 de março de 2002. Brasília, DF, 2002d.

BRASIL. Ministério da Educação. Conselho Nacional de Educação. Parecer CNE/CES 15 de 02 de fevereiro de 2005. Solicitação de esclarecimento sobre as resoluções CNE/CP n. 1/2002, que institui diretrizes curriculares nacionais para a formação de professores da educação básica, em nível superior, curso de licenciatura, de graduação plena, e 2/2002, que institui a duração e a carga horária dos cursos de licenciatura, de graduação plena, de formação de professores da educação básica, em nível superior.

CARVALHO, A. M. P \& GIL-PÉREZ, D. Formação de professores de Ciências: Tendências e inovações. 10. ed. São Paulo: Ed Cortez, 2011.

DOS SANTOS, W. L. P. Contextualização no ensino de ciências por meio de temas CTS em uma perspectiva crítica. Ciência \& Ensino, v. 1, 2007.

DUTRA, E. F. Possibilidades para a articulação entre teoria e prática em cursos de licenciatura. 2010. 354f. Dissertação (Mestrado em Educação). Universidade Federal Santa Maria, Santa Maria. 2010.

FABRICIO, M. F. L., JÓFILI, Z. M. S., MARTINS, L. S. S., LEÃO, A. M. A. C. A. Compreensão das Leis de Mendel por alunos de Biologia na Educação Básica e na Licenciatura. Ensaio. Pesquisa em Educação em Ciências, v.8, p.1 - 21, 2006.

GADOTTI, M. Perspectivas atuais da educação. São Paulo em perspectiva, v. 14, n. 2, p. 03-11, 2000.

LIGUORI, L. M. As novas tecnologias da informação e da comunicação no campo dos velhos problemas e desafios educacionais. IN: LITWIN, EDITH (org). Tecnologia Educacional: políticas, histórias e propostas. Porto Alegre: Artes Médicas, 1997.

LOPES, F. M. B. Ciclo celular: estudando a formação de conceitos no ensino médio. 2007.101f. Dissertação (Mestrado em Ensino de Ciências). Universidade Federal Rural de Pernambuco, Recife. 2007.

MIRANDA, M. G. de. O professor pesquisador e sua pretensão de resolver a relação entre a teoria e a prática na formação de professores. In: O Papel da pesquisa na formação e na prática dos professores. 5 ed, Campinas: Papirus, 2006, p.129-143.

MIZUKAMI, M. G. N. Aprendizagem da docência: algumas contribuições de LS Shulman. Educação, v. 29, n. 2, p. 33-50, 2004

PEREIRA, A. F. Diagnóstico das dificuldades de articulação e sobreposição dos conceitos básicos da genética utilizando jogos didáticos. 2008. 191f. Dissertação (Mestrado em Ensino de Ciências). Universidade Federal Rural de Pernambuco, Recife, 2008.

PERRENOUD, P. Dez novas competências para ensinar. Porto Alegre: Artmed Editora, 2000.

SHULMAN, L. S. Knowledge and teaching: foundations of the new reform. Harvard Educational Review, 57 (1), 1987, p. 1-22.

SHULMAN. Those Who Understand: knowledge Growth in Teaching. Educational Researcher, p.414. 1986.

ZABALZA, M. A. Competencias docentes del profesorado universitario. Calidad y desarrollo profesional. Madrid-ES: Editora Narcea, 2006, 253p. 